\title{
Effect of Laser Radiation on Free Radicals in Human Cancer G361 Cells
}

\author{
M. LatochA ${ }^{a}$, B. Pilawa ${ }^{b, *}$, M. Zdibel ${ }^{b}$ And T. WilczoK ${ }^{c}$
}

Departments of ${ }^{a}$ Cell Biology, ${ }^{b}$ Medical Physics, ${ }^{c}$ Molecular Biology and Medical

Genetics, School of Pharmacy, Medical University of Silesia

Narcyzów 1, 41-200 Sosnowiec, Poland

\begin{abstract}
EPR spectroscopy was used to the examination of free radicals evolution in cancer G361 cells during photodynamic therapy. The cancer cells were cultured with photosensitizer ALA and irradiated with $635 \mathrm{~nm}$ light by laser. The number of cells was determined microscopically. The decrease in the cell number and the increase in free radicals, obtained for G361 cells cultured with ALA and irradiated with laser, were stronger than relevant changes for the cells which were only irradiated with laser. The studied melanotic cells susceptible for photodynamic therapy differ from the other melanotic SK human cancer cells by fast spin-lattice relaxation processes. Slow spinlattice relaxation processes exist in the studied earlier non susceptible for photodynamic therapy SK human melanoma cells.
\end{abstract}

PACS numbers: $76.30 . \mathrm{Rn}$

\section{Introduction}

Free radicals in melanotic human melanoma G361 cells after photodynamic therapy (PDT) were studied by EPR spectroscopy. The pathological G361 skin cells contain a large amount of paramagnetic melanin biopolymer. During photodynamic therapy the photosensitised cells absorb the radiation of adequate wavelength and free radicals are created. The aim of this work was to compare laser radiation effects on free radicals in the examined cancer cells both without and with ALA photosensitizer.

\section{Experimental}

\subsection{Samples}

The human cancer cells obtained from G361 line were grown in monolayer cultures in McCoy's medium (Sigma) with $1.5 \mathrm{mM}$ glutamine. The medium

*corresponding author; e-mail: bpilawa@slam.katowice.pl 
was supplemented with $10 \%$ fetal bovine serum (FBS, Gibco) and $1 \%$ penicillin $(10000 \mathrm{IU} / \mathrm{ml})$ and streptomycin $(10 \mathrm{mg} / \mathrm{ml})$. The culture was incubated at $37^{\circ} \mathrm{C}$ and in humid atmosphere of $5 \% \mathrm{CO}_{2}$. In the PDT studies cells were maintained in a proper medium containing $100 \mu \mathrm{g} / \mathrm{ml}$ of ALA (Wirkstoff) for approximately 1 hour and were irradiated with $635 \mathrm{~nm}$ light by laser model Terapus R 635/650 (Accuro). The number of cells in $1 \mathrm{ml}$ of the studied samples was determined microscopically.

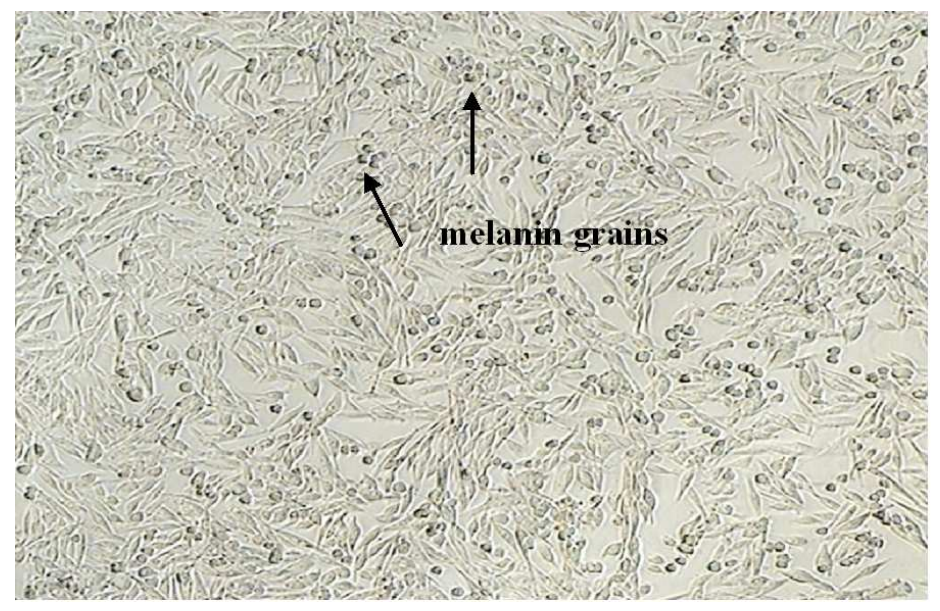

Fig. 1. G361 cell culture.

The microscopic observations of the studied cell cultures are shown in Fig. 1. The cancer cells grow on the area of the culture flask and after several days they produce melanin. Melanin grains (marked) in G361 cells are clearly visible in this picture. Melanin biopolymer affects susceptibility of the cells on photodynamic therapy.

\subsection{EPR meausrements}

EPR spectra were measured for the following G361 cancer cells: original cells (without any treatment), the cells cultured with ALA, the original cells irradiated with $635 \mathrm{~nm}$ light, and the cells cultured with ALA and irradiated with $635 \mathrm{~nm}$ light. EPR measurements were performed using an X-band $(9.3 \mathrm{GHz})$ spectrometer with modulation of magnetic field of $100 \mathrm{kHz}$. Detection of EPR spectra was done by RAPID SCAN UNIT produced by JAGMAR-Kraków firm. EPR lines were accumulated 200 times, because of their low intensities. The time of single EPR line measurement was $10^{-4} \mathrm{~s}$. Resonance absorption curves were recorded with low microwave power of $\sim 0.7 \mathrm{~mW}$. The EPR spectra were analysed using ELF1 program of JAGMAR firm. The following parameters of the first-derivative EPR spectra were determined: $g$-factor, linewidth $\left(\Delta B_{\mathrm{pp}}\right)$, amplitude $(A)$, and integral intensity $(I)$. Amplitudes and integral intensities were 
divided by volume of the tested cells in tubes. The relative changes of EPR parameters caused by ALA photosensitizer or laser radiation were analysed. Influence of microwave power $(0.7-70 \mathrm{~mW})$ on the EPR spectra was also examined.

\section{Results and discussion}

The number of cells in G361 culture does not change considerably after treating by ALA, while the strong decrease in cells number was observed after laser irradiation of both the original cells and cells cultured with ALA photosensitizer.

The very broad EPR lines with linewidths $\Delta B_{\mathrm{pp}}$ in the range of $2.62-2.98 \mathrm{mT}$ and $g$-factor 2.0032 were measured for the studied cells. Linewidths and integral intensities of the measured EPR lines are presented in the Table.

\section{TABLE}

Parameters of EPR spectra of G361 cancer cells: linewidths $\left(\Delta B_{\mathrm{pp}}\right)$ and integral intensities $(I)$. Integral intensities were calculated in arbitrary units (per volumetric unit).

\begin{tabular}{c|c|c}
\hline \hline G361 cells & $\begin{array}{c}\Delta B_{\mathrm{pp}} \\
{[ \pm 0.04 \mathrm{mT}]}\end{array}$ & $\begin{array}{c}I \\
{[ \pm 0.2]}\end{array}$ \\
\hline control cells & 2.62 & 0.9 \\
cells+ALA & 2.98 & 1.3 \\
cells+LASER & 2.86 & 1.7 \\
cells+ALA+LASER & 2.76 & 2.1
\end{tabular}

EPR lines of the studied human melanoma G361 cells probably mainly result from $o$-semiquinone free radicals of melanin biopolymer. A high content of melanin characterizes G361 cells. o-Semiquinone free radicals exist in melanins in high amounts $\left(10^{17}-10^{21} \mathrm{spin} / \mathrm{g}\right)[1,2]$. The broken bonds in unsaturated fatty acids in the cells are also responsible for their paramagnetism. Similar EPR signals were detected for the others melanotic cancer cells [3].

Integral intensities of the analysed spectra of G361 cells increased as follow: the original cells $<$ the original cells irradiated by laser $<$ the cells cultured with ALA $<$ the cells cultured with ALA and irradiated by laser (Table). The highest formation of free radicals in G361 cells cultured with ALA and irradiated corresponds to the degradation of the cells (the lowest amount of the cells in the culture). The above relations obtained for G361 cells differ from those observed for SK melanotic human melanoma cells [4]. The high and low susceptibility to PDT of G361 and SK human melanoma cells was proved, respectively. After photodynamic therapy a higher concentration of free radicals was measured for G361 cells than for SK human melanoma cells. 


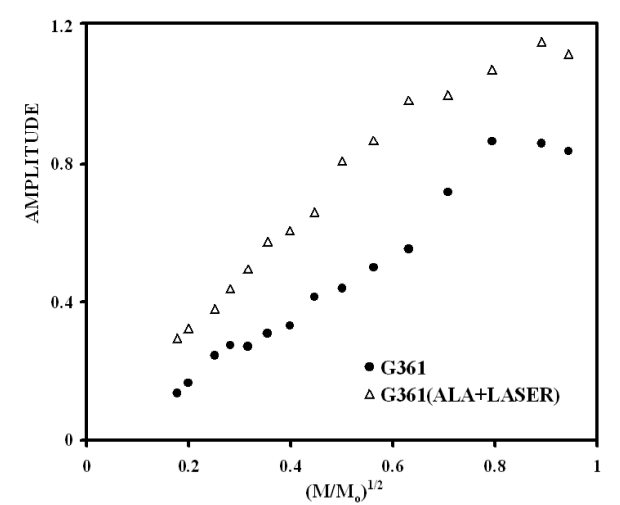

Fig. 2. Changes of amplitudes of EPR lines of control G361 cells and G361 cells treated by ALA and laser. $M-$ microwave power used during the measurement of EPR line, $M_{0}$ — total microwave power produced by klystron $(70 \mathrm{~mW})$.

Fast spin-lattice relaxation processes occur in both control and laser irradiated cancer G361 cells. EPR lines of control and irradiated cells do not saturate in the used range of microwave power (Fig. 2). Melanotic SK cells which are non susceptible for PDT are characterized by slow spin-lattice relaxation processes [3].

\section{Conclusion}

Free radicals formation in the studied cancer cells was observed after both reactions with photosensitizer ALA and after laser radiation. The strongest free radicals generation appears in the irradiated cell system treated with ALA. Degradation of the tumor cells was also the highest in irradiated culture containing ALA. The performed EPR measurements and microscopic observations confirmed susceptibility of G361 cancer cells to photodynamic therapy.

\section{References}

[1] R.C. Sealy, J.S. Hyde, C.C. Felix, I.A. Menon, G. Prota, Science 217, 545 (1982).

[2] M. Matuszczyk, E. Buszman, B. Pilawa, T. Witoszyńska, T. Wilczok, Chem. Phys. Lett. 394, 366 (2004).

[3] M. Latocha, B. Pilawa, E. Chodurek, E. Buszman, T. Wilczok, Appl. Magn. Reson. 26, 339 (2004).

[4] M. Latocha, B. Pilawa, J. Dudek, T. Biniszkiewicz, L. Kozdrowska, A. Sieroń, T. Wilczok, Medical Physics XX, Suppl. 1, 69 (2004). 